\title{
ORIGINAL
}

\section{Maintenance fluid therapy and fluid creep impose more significant fluid, sodium, and chloride burdens than resuscitation fluids in critically ill patients: a retrospective study in a tertiary mixed ICU population}

Niels Van Regenmortel ${ }^{1,2^{*}}$ (D) Walter Verbrugghe ${ }^{1}$, Ella Roelant ${ }^{3}$, Tim Van den Wyngaert $^{4,5}$ and Philippe G. Jorens ${ }^{1,5}$

() 2018 The Author(s)

\begin{abstract}
Purpose: Research on intravenous fluid therapy and its side effects, volume, sodium, and chloride overload, has focused almost exclusively on the resuscitation setting. We aimed to quantify all fluid sources in the ICU and assess fluid creep, the hidden and unintentional volume administered as a vehicle for medication or electrolytes.
\end{abstract}

Methods: We precisely recorded the volume, sodium, and chloride burdens imposed by every fluid source administered to 14,654 patients during the cumulative 103,098 days they resided in our 45-bed tertiary ICU and simulated the impact of important strategic fluid choices on patients' chloride burdens. In septic patients, we assessed the impact of the different fluid sources on cumulative fluid balance, an established marker of morbidity.

Results: Maintenance and replacement fluids accounted for $24.7 \%$ of the mean daily total fluid volume, thereby far exceeding resuscitation fluids (6.5\%) and were the most important sources of sodium and chloride. Fluid creep represented a striking 32.6\% of the mean daily total fluid volume [median $645 \mathrm{~mL}$ (IQR 308-1039 mL)]. Chloride levels can be more effectively reduced by adopting a hypotonic maintenance strategy [a daily difference in chloride burden of $30.8 \mathrm{mmol}(95 \% \mathrm{Cl} 30.5-31.1)$ ] than a balanced resuscitation strategy [daily difference $3.0 \mathrm{mmol}(95 \% \mathrm{Cl} 2.9-3.1)$ ]. In septic patients, non-resuscitation fluids had a larger absolute impact on cumulative fluid balance than did resuscitation fluids.

Conclusions: Inadvertent daily volume, sodium, and chloride loading should be avoided when prescribing maintenance fluids in view of the vast amounts of fluid creep. This is especially important when adopting an isotonic maintenance strategy.

Keywords: Fluid therapy, Maintenance fluids, Fluid overload, Fluid creep, Chloride, Sodium, Hyperchloremia

\footnotetext{
*Correspondence: niels.vanregenmortel@uza.be

${ }^{1}$ Department of Intensive Care Medicine, Antwerp University Hospital,

Wilrijkstraat 10, 2650 Edegem, Antwerp, Belgium

Full author information is available at the end of the article
} 


\section{Introduction}

In recent years, interest in intravenous fluid therapy and its side effects has increased exponentially. Many trials have attempted to settle the colloid/crystalloid debate, while others have provided guidance on selecting the optimal crystalloid solution [1-6]. Much attention has been paid to the role of chloride, which may have a detrimental effect on kidney function but can be reduced through the use of chloride-poor solutions [7-10]. Strikingly, virtually all of these scientific endeavors focused exclusively on the resuscitation setting, in which patients need large amounts of fluids over a very short time period. In clinical reality, though, many fluids and electrolytes are administered for other reasons: maintenance fluid therapy, prescribed to provide water and electrolytes when patients are unable to ingest food or fluids; and replacement therapy, for existing or developing losses that cannot be covered by oral or enteral intake. Moreover, an undocumented but potentially substantial volume of fluids is administered unintentionally as a vehicle for intravenous, oral, or enteral medication. We term this insidious and often-overlooked volume fluid creep, by analogy to a phenomenon frequently encountered in burn care resuscitation, where it refers to the volume administered unintentionally in excess of what is calculated using the Parkland formula $[11,12]$.

We aimed to look beyond the well-studied resuscitation fluids by mapping out detailed absolute and relative proportions of volume, sodium, and chloride of every fluid source in our 45-bed tertiary intensive care unit (ICU). This would include not only fluid prescription per se (maintenance, replacement, and resuscitation) but also blood products, nutritional and oral intake, and a detailed calculation of fluid creep. This granular dataset would also allow us to simulate the difference in chloride burden caused by strategic fluid choices that continue to be a subject of discussion: balanced versus unbalanced resuscitation fluids and hypotonic versus isotonic maintenance fluids. Finally, since a positive cumulative fluid balance is an established, independent marker of poor outcomes in septic patients, we wished to assess the contribution of the various fluid sources to this parameter in this important patient subgroup [13].

\section{Materials and methods}

We conducted a large-scale retrospective cohort study in the 45-bed tertiary intensive care unit (ICU) at the Antwerp University Hospital, Belgium. Since all data were to be completely de-identified, the hospital's institutional review board waived the necessity of obtaining informed consent (directive 14/9/88). We collected data on every adult patient (over 16 years of age) admitted between

\section{Take-home message:}

Volume, sodium and chloride overload due to non-resuscitation solutions and fluid creep deserve more consideration than they were granted in fluid studies up till now and should lead to the downsizing or even avoidance of maintenance fluids whenever possible, whilst handling the need for sufficient electrolytes through concentrated administration. A well considered strategy regarding the tonicity of maintenance solutions could be more effective in reducing the sodium and chloride burden than switching to a balanced resuscitation and replacement strategy.

October 2007 and November 2016. Only the patients undergoing cardiac surgery were excluded from the study because of the difficulty of collecting precise data on fluid rate due to the use of a burette to administer fluids and electrolytes. All data were retrieved from the patient data management system (PDMS) (Metavision, iMDsoft, Düsseldorf, Germany). Demographic data included age, gender, body weight, simplified acute physiology score (SAPS-3), and admission type [14]. A more detailed description of the study population, including precise data on admission diagnosis, biochemistry data, blood gas analysis parameters, and the occurrence of acute kidney injury and renal replacement therapy in a representative sample $(n=8830)$ of the current study cohort, was previously published [9].

The dataset consisted of data on every day of every patient's ICU stay, from time of admission until discharge, and detailed all sources of fluids administered: crystalloids, colloids, blood products, enteral and parenteral nutritional products, and oral intake (water, tea, soup, etc.). We also collected precise data on the concentrated electrolytes added to these fluids or administered separately. We defined fluid creep as the sum of the volumes of these electrolytes, the small volumes to keep venous lines open (saline or glucose $5 \%$ ), and the total volume used as a vehicle for medication. To measure the last of these, we retrieved the total daily volumes of every possible water source (thus including the precise volumes of all medications) and subtracted the aforementioned volumes that had already been retrieved separately. Subsequently, we calculated the exact amount of sodium and chloride per fluid administered per day (unavailable only for oral intake and medication). We then reduced this enormous dataset of over 500,000 lines to one line per patient per day, divided into five fluid types: resuscitation, maintenance/replacement, nutrition/oral intake, blood products, and fluid creep. Glucose-free isotonic crystalloids (Hartmann's, PlasmaLyte ${ }^{\circledR}$ (Baxter, Deerfield, Illinois, USA) and rarely $\mathrm{NaCl} 0.9 \%$ ) are used for both resuscitation and replacement. For the purposes of this study, we opted to consider these solutions resuscitation fluids when they were administered at a rate above 
$166 \mathrm{~mL} / \mathrm{h}$ (equal to $1 \mathrm{~L}$ over $6 \mathrm{~h}$ ) and replacement solutions when administered at lower rates. Fluid balance was calculated by subtracting cumulative daily fluid output from the total volume administered daily.

To improve the external validity of our findings, it is important to disclose our ICU's fluid policy in detail. (1) Maintenance solutions always contain glucose on our ICU, to allow them to be hypotonic, but not hypoosmolal. As many other fluids (resuscitation, medication) are already being administered routinely, it is our policy to limit maintenance solutions to a maximum of $1 \mathrm{~L}$, supplemented by $1 \mathrm{~g}$ of magnesium sulfate and $20-40 \mathrm{mmol}$ of potassium chloride or-in case of hypophosphatemia-potassium phosphate. In case of hypokalemia, extra potassium is added through a separate infusion. Maintenance solutions are usually hypotonic (3-6 g of sodium chloride per liter), though this can be adjusted depending on the patient's clinical needs [15]. Once nutritional support is initiated, maintenance fluids are reduced accordingly, to a minimum of $100 \mathrm{~mL} /$ day as a vehicle for electrolyte substitution. (2) All resuscitation solutions used on our ICU are balanced, whether crystalloids (Hartmann's, PlasmaLyte ${ }^{\circledR}$ ) or synthetic colloids (Geloplasma ${ }^{\circledR}$, Fresenius Kabi, Bad Homburg, Germany). The use of the latter has diminished substantially since 2014 in favor of crystalloids. Hydroxyethyl starches were used very rarely, and their use ceased completely after 2012 [1, 2]. Hyperoncotic human albumin 20\% is sometimes used in cases of severe hypoalbuminemia in combination with fluid overload, but rarely in the resuscitation setting. (3) Replacement solutions vary in terms of glucose and electrolyte content depending on the clinical situation for which they are prescribed.

Since we were also interested in the potential clinical difference between balanced and unbalanced fluids in terms of chloride burden, we calculated the hypothetical amount of chloride that would have been administered if every balanced solution in our dataset (Hartmann's and PlasmaLyte ${ }^{\circledR}$; chloride 110 and $98 \mathrm{mmol} / \mathrm{L}$, respectively) had been replaced by $\mathrm{NaCl} 0.9 \%$ (chloride $154 \mathrm{mmol} / \mathrm{L}$ ) and if Geloplasma ${ }^{\circledR}$ (chloride $100 \mathrm{mmol} / \mathrm{L}$ ) had been replaced by an unbalanced gelatin (chloride $120 \mathrm{mmol} / \mathrm{L}$ ). Similarly, we calculated the hypothetical difference in chloride loading if all maintenance solutions had been isotonic by identifying every maintenance fluid with a tonicity lower than $295 \mathrm{mmol} / \mathrm{L}$ and increasing its cumulative sodium and chloride content to $295 \mathrm{mmol} / \mathrm{L}$.

Data handling and statistical analysis were performed using Stata 14 (StataCorp LP, Texas, USA). Means were reported \pm standard deviations (SD) and medians with their interquartile ranges (IQR). Paired $t$ tests were used to compare dependent means. To assess the proportional impact of resuscitation and non-resuscitation fluids on cumulative fluid balance in septic patients, a linear mixed-effects model was fitted for cumulative fluid balance during ICU stay. The combined cumulative volume of maintenance, replacement, and fluid creep, time, and their interaction were treated as fixed effects, with a random intercept for each patient. The model was further adjusted for resuscitation volume and its interaction with time and SAPS-3 score. To achieve this, we omitted data from the ICU day on which the patient received diuretics or renal replacement therapy, as these affect fluid balance artificially and independently of fluid intake. Statistical significance was set at a $p$ value of less than 0.05 (twosided) for all tests. Graphics were created with Stata 14, Microsoft Excel and R.

\section{Results}

Details on the study population can be found in Table 1. Almost half of the 14,654 patients were admitted for a medical reason. The mean length of stay was $5.9 \pm 10.5$ days equating to a total of 103,098 ICU days with a mean duration of $20.3 \pm 6.7 \mathrm{~h}$.

Figure 1 summarizes the volumes and sodium/chloride burdens per fluid type administered during an average day of ICU stay. Resuscitation fluids, consisting of colloids and rapidly administered crystalloids, accounted for $6.5 \%$ of the total mean daily fluid volume and means of 21 and $17 \mathrm{mmol}$ per day of sodium and chloride, respectively. On the median ICU day, no resuscitation fluids were administered. Maintenance/replacement solutions with their added electrolytes accounted for $24.7 \%$ of daily fluid intake and means of $68 \mathrm{mmol}$ of sodium and $79 \mathrm{mmol}$ of chloride per day. Fluid creep represented an enormous part of the daily administered fluids [median $645 \mathrm{~mL}$ (IQR 308-1039) or 32.6\% of the mean daily fluid volume]. Separately administered concentrated electrolytes, mainly potassium chloride, were responsible for an additional daily chloride load of $10 \pm 33 \mathrm{mmol}$, more than half of the burden caused by resuscitation fluids. The mean daily sodium burden was $131 \pm 137 \mathrm{mmol}$ per day of ICU stay, even without considering the abundant medications dissolved in $\mathrm{NaCl} 0.9 \%$. As insights into fluid therapy evolved considerably in recent years, we also include data on the 10-year temporal trend in our ICU in Supplementary File 1.

Figure 2 shows the shift in the proportion of the different fluid sources being administered over the first 5 days of ICU stay. After extensive initial use of resuscitation, their use diminished rapidly (19.6-4.2\% of total mean daily fluid volume over the course of 5 days) in favor of nutritional intake. Despite decreasing slightly over time, maintenance/replacement solutions remained an important component of fluid therapy (41.3-24.4\%), especially considering that dehydration and pre-admission fluid 
Table 1 Characteristics of patient population, days of ICU stay, and fluid parameters

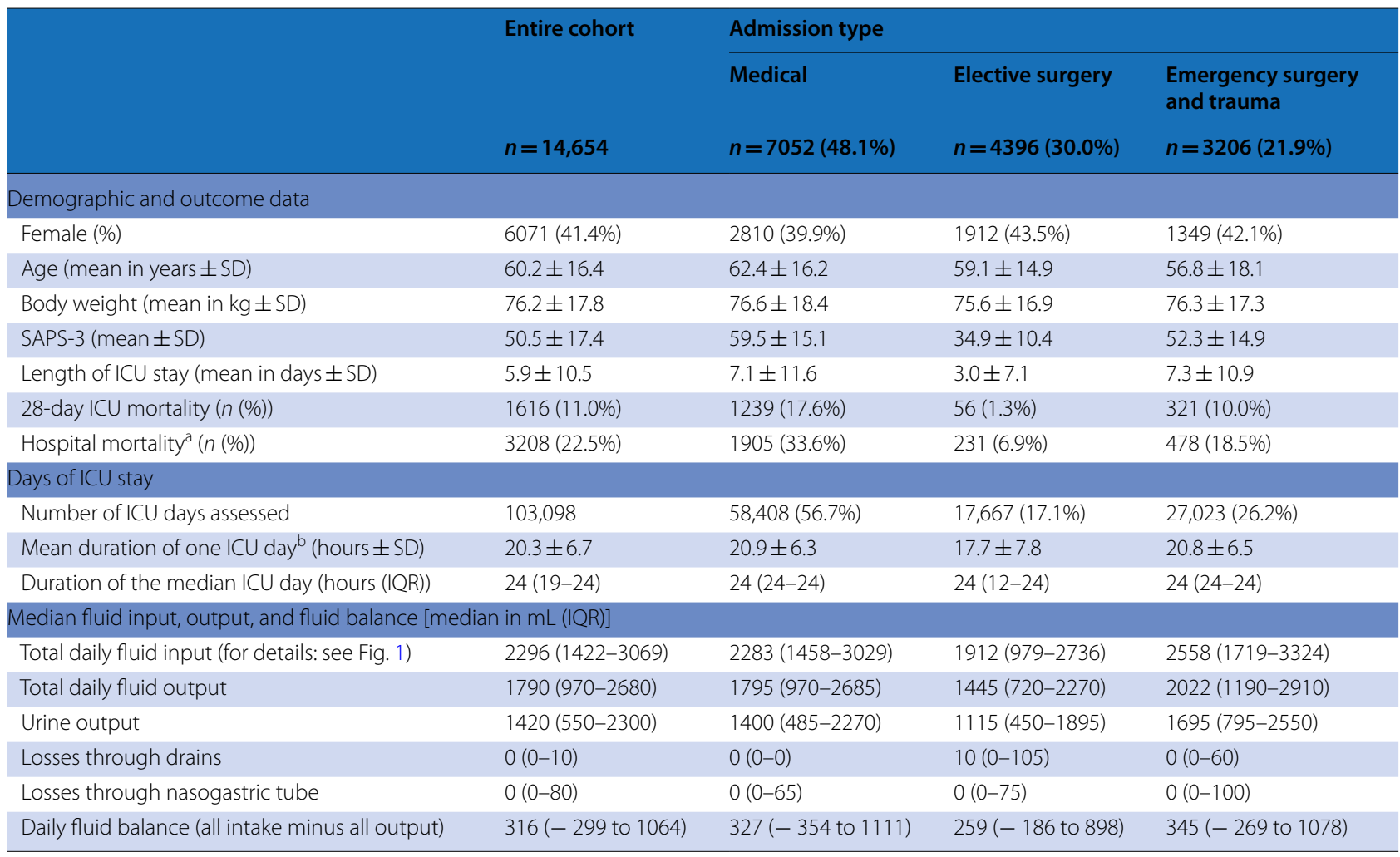

$S D$ standard deviation, IQR interquartile range

a If a patient was admitted more than once, only one admission counted for hospital mortality

${ }^{b}$ First day of admission runs from time of admission until 8:00 AM; day of discharge runs from 8:01 AM until time of discharge

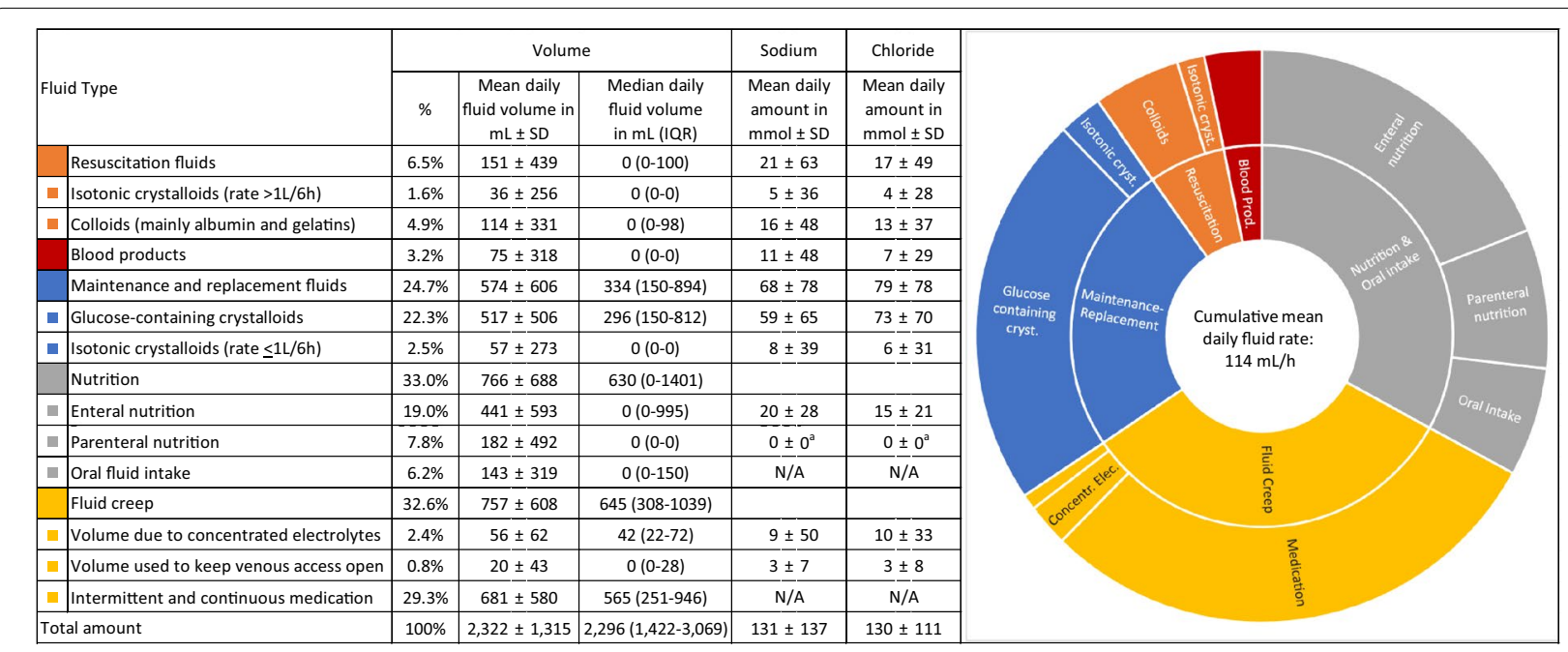

Fig. 1 Proportion, mean, and median fluid volumes, and mean sodium and chloride burdens of the different fluid types (average of 14,654 patients on their cumulative 103,098 days of ICU stay), including a graphic representation of the distribution of the different mean daily fluid volumes. Mean duration of one ICU day, $20.3 \pm 6.7 \mathrm{~h}$. SD standard deviation, IQR interquartile range, N/A data not available. ${ }^{\mathrm{a}}$ To ensure optimal electrolyte management in our ICU, only electrolyte-free formulas of parenteral nutrition are prescribed, with separate administration of electrolytes 


\begin{tabular}{|c|c|c|c|c|c|c|}
\hline \multirow{2}{*}{\multicolumn{2}{|c|}{\begin{tabular}{|l|} 
\\
First day of admission
\end{tabular}}} & \multirow{3}{*}{$\begin{array}{c}\text { Medical } \\
n=7,052 \\
21.1 \%\end{array}$} & \multirow{3}{*}{$\begin{array}{c}\begin{array}{c}\text { Elective } \\
\text { Surgery }\end{array} \\
\mathrm{n}=4,396 \\
16.4 \%\end{array}$} & \multirow{3}{*}{$\begin{array}{c}\begin{array}{c}\text { Emergency } \\
\text { Surgery \& } \\
\text { Trauma }\end{array} \\
\mathrm{n}=3,206 \\
20.6 \%\end{array}$} & \multicolumn{2}{|r|}{ Whole cohort } \\
\hline & & & & & $\mathrm{n}=14,654$ & \\
\hline$\square$ & Resuscitation fluids & & & & $19.6 \%$ & \\
\hline 口 & Blood products & $8.1 \%$ & $2.8 \%$ & $8.7 \%$ & $6.6 \%$ & \\
\hline 口 & Maintenance/Replacemen & $37.0 \%$ & $48.9 \%$ & $40.1 \%$ & $41.3 \%$ & \\
\hline$\square$ & Nutrition and Oral fluids & $7.7 \%$ & $4.4 \%$ & $5.4 \%$ & $6.2 \%$ & \\
\hline$\square$ & Fluid creep & $26.0 \%$ & $27.4 \%$ & $25.2 \%$ & $26.3 \%$ & \\
\hline \multicolumn{2}{|r|}{ Total mean daily fluid volume } & $1,682 \pm 1,365$ & $1,771 \pm 849$ & $1,824 \pm 1,544$ & $1,739 \pm 1,280$ & \\
\hline \multicolumn{2}{|r|}{ Mean cumulative fluid balance } & $437 \pm 1,524$ & $219 \pm 1,035$ & $520 \pm 1,531$ & $390 \pm 1,402$ & \\
\hline \multicolumn{2}{|c|}{ Mean duration of ICU-day ${ }^{a}$} & $14.3 \pm 5.3$ & $16.6 \pm 3.2$ & $13.4 \pm 5.3$ & $14.8 \pm 4.9$ & \\
\hline \multicolumn{2}{|r|}{ Second day of admission } & $n=6,834$ & $n=4,290$ & $n=3,130$ & $\mathrm{n}=14,254$ & \\
\hline a & Resuscitation fluids & $10.7 \%$ & $10.7 \%$ & $10.5 \%$ & $10.6 \%$ & \\
\hline 口 & Blood products & $4.2 \%$ & $1.9 \%$ & $4.2 \%$ & $3.6 \%$ & \\
\hline 口 & Maintenance/Replacemen & $38.8 \%$ & $49.9 \%$ & $46.4 \%$ & $43.4 \%$ & \\
\hline$\square$ & Nutrition and Oral fluids & $16.2 \%$ & $12.2 \%$ & $11.2 \%$ & $14,0 \%$ & \\
\hline$\square$ & Fluid creep & $30.0 \%$ & $25.3 \%$ & $27.7 \%$ & $28.3 \%$ & \\
\hline \multicolumn{2}{|r|}{ Total mean daily fluid volume } & $2,274 \pm 1,504$ & $1,650 \pm 1,385$ & $2,628 \pm 1,639$ & $2,164 \pm 1,544$ & \\
\hline \multirow{2}{*}{\multicolumn{2}{|c|}{$\begin{array}{l}\text { Mean cumulative fluid balance } \\
\text { Mean duration of ICU-day }\end{array}$}} & $1,020 \pm 2,618$ & $758 \pm 1,720$ & $1,391 \pm 2,412$ & $1,022 \pm 2,346$ & \\
\hline & & $20.3 \pm 7.2$ & $14.4 \pm 9.6$ & $20.1 \pm 7.4$ & $18.5 \pm 8.5$ & \\
\hline \multicolumn{2}{|c|}{ Third day of admission } & $n=5,336$ & $n=2,106$ & $n=2,435$ & $\mathrm{n}=9,877$ & \\
\hline 口 & Resuscitation fluids & $6.5 \%$ & $6.4 \%$ & $6.8 \%$ & $6.5 \%$ & \\
\hline$\square$ & Blood products & $3.4 \%$ & $2.4 \%$ & $3.0 \%$ & $3.1 \%$ & \\
\hline 口 & Maintenance/Replacemen & $31.4 \%$ & $41.1 \%$ & $40.5 \%$ & $35.7 \%$ & \\
\hline$\square$ & Nutrition and Oral fluids & $25.4 \%$ & $21.0 \%$ & $18.8 \%$ & $22.8 \%$ & \\
\hline$\square$ & Fluid creep & $33.4 \%$ & $29.1 \%$ & $30.8 \%$ & $31.9 \%$ & \\
\hline \multicolumn{2}{|r|}{ Total mean daily fluid volume } & $2,172 \pm 1,338$ & $1,788 \pm 1,311$ & $2,501 \pm 1,568$ & $2,171 \pm 1,414$ & \\
\hline \multicolumn{2}{|r|}{ Mean cumulative fluid balance } & $1,517 \pm 3,590$ & $1,709 \pm 2,607$ & $2,223 \pm 3,310$ & $1,732 \pm 3,346$ & \\
\hline \multicolumn{2}{|c|}{ Mean duration of ICU-day ${ }^{a}$} & $20.2 \pm 7.4$ & $16.5 \pm 9.1$ & $20.0 \pm 7.4$ & $19.4 \pm 7.9$ & \\
\hline \multicolumn{2}{|c|}{ Fourth day of admission } & $n=4,153$ & $\mathrm{n}=1,247$ & $\mathrm{n}=1,878$ & $\mathrm{n}=7,278$ & \\
\hline$\square$ & Resuscitation fluids & $4.5 \%$ & $5.3 \%$ & $5.0 \%$ & $4.8 \%$ & \\
\hline 口 & Blood products & $2.8 \%$ & $2.0 \%$ & $2.2 \%$ & $2.5 \%$ & \\
\hline$\square$ & Maintenance/Replacemen & $25.9 \%$ & $32.6 \%$ & $34.5 \%$ & $29.4 \%$ & \\
\hline$\square$ & Nutrition and Oral fluids & $31.7 \%$ & $27.9 \%$ & $25.9 \%$ & $29.4 \%$ & \\
\hline$\square$ & Fluid creep & $32.8 \%$ & $31.7 \%$ & $32.4 \%$ & $33.8 \%$ & \\
\hline \multicolumn{2}{|r|}{ Total mean daily fluid volume } & $2,201 \pm 1,256$ & $1,761 \pm 1,257$ & $2,536 \pm 1,412$ & $2,212 \pm 1,322$ & \\
\hline \multicolumn{2}{|r|}{ Mean cumulative fluid balance } & $1,922 \pm 4,430$ & $2,326 \pm 3,395$ & $2,961 \pm 4,076$ & $2,259 \pm 4,200$ & \\
\hline \multicolumn{2}{|r|}{ Mean duration of ICU-day ${ }^{a}$} & $20.8 \pm 6.9$ & $16.8 \pm 9.1$ & $20.7 \pm 7.0$ & $20.1 \pm 7.5$ & \\
\hline \multicolumn{2}{|c|}{ Fifth day of admission } & $n=3,368$ & $\mathrm{n}=755$ & $\mathrm{n}=1,520$ & $n=5,643$ & \\
\hline$\square$ & Resuscitation fluids & $4.1 \%$ & $4.3 \%$ & $4.2 \%$ & $4.2 \%$ & \\
\hline 口 & Blood products & $2.9 \%$ & $1.8 \%$ & $2.0 \%$ & $2.5 \%$ & \\
\hline$\square$ & Maintenance/Replacemen & $21.2 \%$ & $26.9 \%$ & $29.6 \%$ & $24.4 \%$ & \\
\hline 口 & Nutrition and Oral fluids & $36.1 \%$ & $33.5 \%$ & $30.9 \%$ & $34.3 \%$ & \\
\hline & Fluid creep & $35.7 \%$ & $33.4 \%$ & $33.3 \%$ & $34.7 \%$ & \\
\hline & al mean daily fluid volume & $2,224 \pm 1,222$ & $1,935 \pm 1,314$ & $2,563 \pm 1,364$ & $2,277 \pm 1,289$ & \\
\hline & an cumulative fluid balance & $2,216 \pm 5,111$ & $2,834 \pm 4,147$ & $3,404 \pm 4,613$ & $2,619 \pm 4,887$ & \\
\hline & an duration of ICU-day ${ }^{a}$ & $21.1 \pm 6.7$ & $18.1 \pm 8.6$ & $20.9 \pm 6.7$ & $20.6 \pm 7.0$ & \\
\hline
\end{tabular}

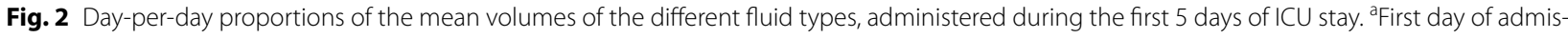
sion runs from time of admission until 8:00 AM; day of discharge runs from 8:01 AM until time of discharge

losses should have been corrected during the first 1 or 2 days. Fluid creep was responsible for at least a quarter of the mean total volume on any given day and became the main fluid source from the fourth day onwards. The absolute and relative volumes of the various fluid sources appeared to be remarkably similar in each of the admission-type subgroups (medical, elective surgery, emergency surgery, and trauma), apart from the slightly lower 


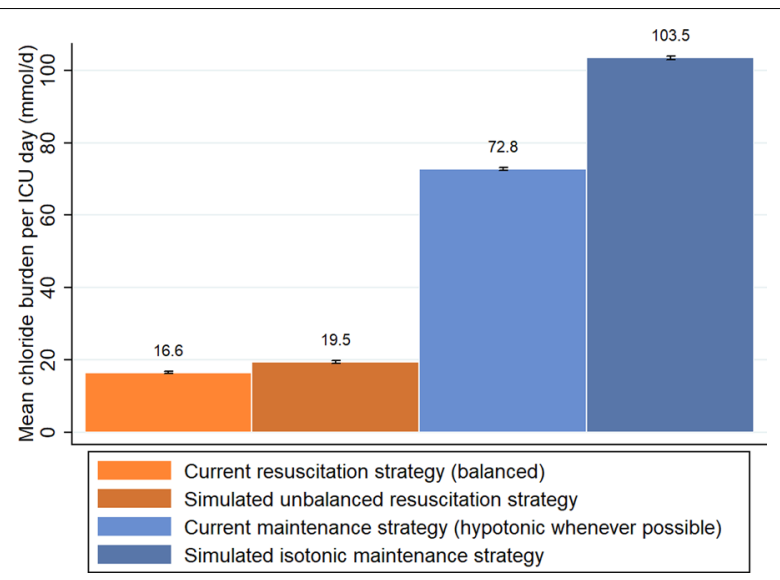

Fig. 3 Light and dark orange (left): actual chloride administration due to balanced resuscitation fluids as retrieved from the dataset, flanked by the simulated amount if these had been unbalanced. Light and dark blue (right): actual chloride administration due to maintenance fluid strategy as retrieved from the dataset, in which hypotonic fluids were prescribed if the clinical situation allowed, flanked by the simulated amount if these fluids had been isotonic. Black bars represent standard error bars

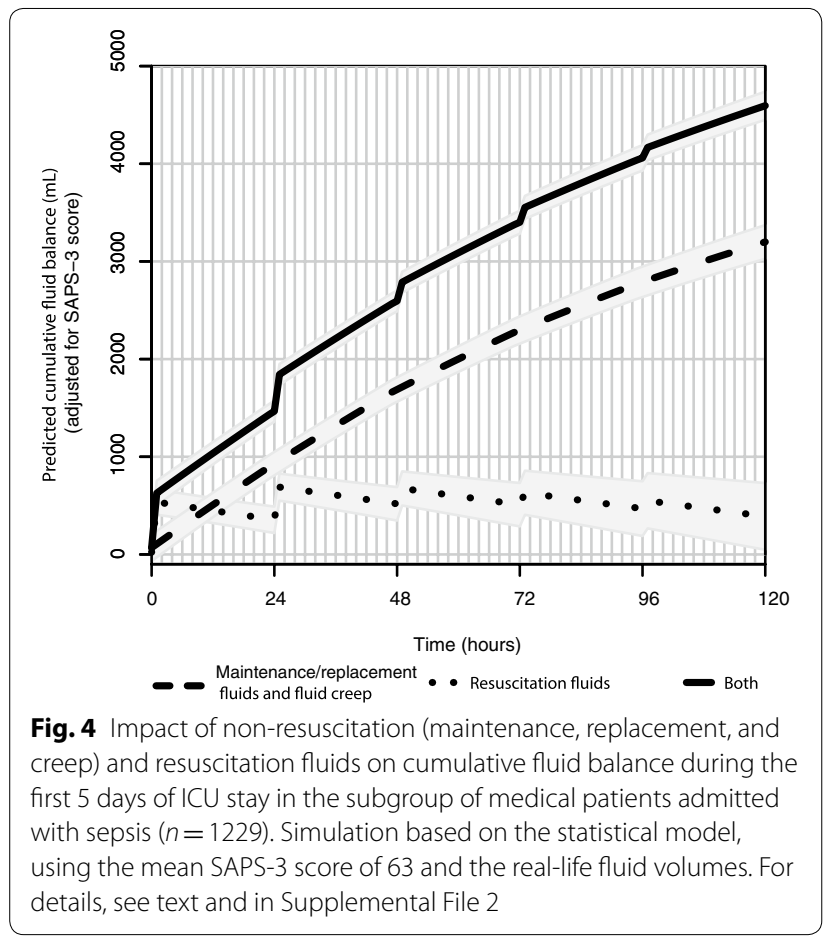

volumes of resuscitation fluids administered during the first few days following admission after elective surgery.

Figure 3 demonstrates that hypothetically changing the type of resuscitation fluid from our current balanced to an unbalanced strategy would have led to a mean daily increase in chloride burden of $3.0 \mathrm{mmol}$ (95\% CI 2.9-3.1).
This is in sharp contrast to the additional $30.8 \mathrm{mmol}$ of chloride (95\% CI 30.5-31.1) that would have been administered daily if every hypotonic maintenance fluid we administered had been isotonic.

Figure 4 shows a simulation of the first 5 days of admission based on the statistical model (Supplementary File 2) for the impact of non-resuscitation fluids (maintenance, replacement, and fluid creep) compared to resuscitation fluids on cumulative fluid balance in the subgroup of medical patients admitted for sepsis $(n=1229 ; 4171$ days of ICU stay). Although resuscitation fluids have twice the "per milliliter" impact on cumulative fluid balance (linear regression coefficient 1.0; 95\% CI 0.91-1.09) compared to non-resuscitation fluids (coefficient 0.5 ; 95\% CI $0.46-0.53$ ), the latter play a larger absolute role in this important risk factor for morbidity because of their much larger volumes.

\section{Discussion}

We have taken a novel direction in the important field of intravenous fluid therapy in critically ill patients by looking beyond the fluids that are administered for resuscitation purposes. In our tertiary ICU, a long-standing awareness of the potential harm caused by fluid overload has led to a prescription strategy that involves the reduction of maintenance fluids as soon as nutrition can supply sufficient water and electrolytes. Yet, our real-life, extensive, granular dataset shows that, even in this setting, maintenance solutions continue to occupy an important place in the daily volume, sodium, and chloride burdens. This is in sharp contrast to the amount of resuscitation fluids, the use of which declines rapidly within the first few days of admission. Our results are even more pronounced than those of two multicenter point-prevalence studies in which resuscitation fluids were defined even more strictly but included blood products [16, 17]. In our view, these findings challenge the dominance of resuscitation fluids in the ongoing fluid debate and call for a realignment of scientific interest.

Although it is difficult to judge the reasons for fluid therapy retrospectively, and sometimes large doses of non-resuscitation fluids will certainly have been necessary, it is plausible that-despite our ICU's fluid policy-maintenance solutions may at times have been prescribed too liberally. We believe the main explanation for this is to be found in the underestimation of the enormous, poorly accounted for volume that patients receive through fluid creep. Originating from intravenous, oral, and enteral medication, concentrated electrolytes, and small volumes that keep intravenous lines open, fluid creep was responsible for a median volume of $645 \mathrm{~mL}$, thereby exceeding all other fluid sources. 
Besides fluid volume, an equally or even more important clinical issue is sodium overload [18-20]. Despite our hypotonic maintenance policy, the total daily sodium administration of $131 \pm 137 \mathrm{mmol}$ far exceeded the guideline-recommended dose of $1 \mathrm{mmol} / \mathrm{kg} /$ day [15]. This was even without taking into account the unmeasured but-according to prior data-substantial sodium burden imposed by the $681 \pm 580 \mathrm{~mL}$ of fluid creep due to countless medications, many of which were probably dissolved in $\mathrm{NaCl}$ 0.9\% [17-19]. Sodium administration in excess of normal dietary intake (recommended to be lower than $2.3 \mathrm{~g}$ or $100 \mathrm{mmol} /$ day in a healthy diet) leads to fluid retention and weight gain, independent of disease, as was demonstrated recently in an experiment comparing isotonic to hypotonic maintenance fluids in healthy subjects [21]. There is ongoing debate-originating from pediatric literature-about the optimal tonicity of maintenance fluids. The main concern among opponents of a hypotonic strategy is the occurrence of hyponatremia [22-26]. We are still awaiting data in adult populations, yet guidelines continue to recommend that maintenance solutions be hypotonic in adults and that sodium levels be monitored in at-risk patients [15, 27]. Regardless of the pediatric strategy chosen, inadvertent non-maintenance sources of sodium have also been demonstrated conclusively in critically ill children [28].

In recent years, much scientific attention has been paid to the potentially detrimental effects of chloride, and its unphysiological presence in $\mathrm{NaCl} 0.9 \%[8,29-31]$. A significant decrease in acute kidney injury was reported following the adoption of a chloride-poor strategy in the ICU when compared to the previous, more chloride-tolerant approach [7]. To the surprise of many, these findings were not prospectively confirmed in the SPLIT trial comparing balanced and unbalanced resuscitation fluids [5]. Although various explanations have been suggested, we believe our results provide a missing piece of the puzzle. As a result of its focus on resuscitation fluids, much larger sources of chloride in the form of maintenance and replacement fluids-which could have augmented Yunos's renal benefit-were overlooked during the trial. To substantiate this hypothesis, we tested differences in chloride administration by simulating an unbalanced resuscitation strategy and found an additional daily chloride burden due to the hypothetical use of $\mathrm{NaCl} 0.9 \%$ and unbalanced colloids that was of negligible clinical importance.

Chloride burden could be reduced far more easily by intervening in the prescription of maintenance fluids, especially by altering their tonicity. A poorly considered maintenance strategy using isotonic fluids such as $\mathrm{NaCl}$ 0.9\% (chloride $154 \mathrm{mmol} / \mathrm{L}$ ) - or even Hartmann's $(110 \mathrm{mmol} / \mathrm{L})$ or PlasmaLyte ${ }^{\circledR}(98 \mathrm{mmol} / \mathrm{L})$-could lead to a substantial and unnecessary chloride overload. Our simulation illustrates that the reduced chloride due to a hypotonic maintenance strategy would far outweigh any gains afforded by a balanced resuscitation/replacement strategy. A final, unintentional chloride source was found in fluid creep. Strikingly, more chloride was administered through chloride-containing electrolyte solutions (10 mmol/day), e.g., potassium chloride, than could be prevented by our balanced resuscitation policy ( $3 \mathrm{mmol} /$ day). Although, again, the nature of our dataset did not allow us to calculate the amount of chloride unintentionally administered by dissolving medication in $\mathrm{NaCl} 0.9 \%$, given the extensive fluid creep involved, this amount is also likely to be substantial $[17,18]$. The use of saline is rarely mandatory as a solvent, so we would advise consulting with hospital pharmacists and using sodium and chloride-poor alternatives whenever possible [32].

Fluid overload is a difficult parameter to grasp clinically, let alone assess scientifically. It is therefore commonly substituted by a positive cumulative fluid balance, which was identified more than 10 years ago as a marker of poor outcome in septic patients, independent of the severity of illness [13]. Since then, a positive cumulative fluid balance has been associated with organ failure, abdominal hypertension, and prolonged perioperative recovery and hospital stay [33-39]. Unlike resuscitation fluids, maintenance solutions are not expected to contribute significantly to disrupted fluid balance, as they are dosed to balance sensible and insensible losses. Our statistical model supports this assumption and shows that resuscitation fluids have a more important "per milliliter" impact on cumulative fluid balance in septic patients than do maintenance and replacement solutions. However, as a result of their large mean volumes and their poor adaptation to the large, overlooked volume caused by fluid creep, non-resuscitation fluids play a prominent role in this worrisome parameter. This is another reason their (over) use should not be regarded as trivial.

Our study has three main limitations. Most importantly, fluid therapy is known to vary not only from country to country, and from hospital to hospital, but also from physician to physician as a result of training, tradition, economic factors, and personal convictions. Judging the external validity of our findings could therefore be challenging. On the other hand, we believe that fluid therapy is taken seriously in our ICU and-while there is always room for improvement-we are convinced that our policy is at the restrictive end of the spectrum. Moreover, we know of numerous hospitals in which glucosefree balanced or unbalanced isotonic crystalloids are the first choice when it comes to maintenance fluids. Therefore, we believe that the situation in many institutions could be at least comparable to and frequently even in 
excess of what we have presented here. Second, to assess fluid-induced harm, we selected cumulative fluid balance as the outcome parameter of our statistical model. It must be acknowledged that a positive fluid balance cannot be viewed as an exclusively detrimental factor, as it could also reflect the correct treatment of an existing intracellular or extracellular fluid deficit. The nature of our dataset did not allow us to judge the appropriateness of the clinical decision to administer fluids retrospectively. Finally, in the current study we assumed that chloride's potential harm lies in the total cumulative dose over the course of an ICU stay. This has not yet been fully established, however, and it is possible that high infusion rates might exert more harm than chloride loads built up slowly over time. On the other hand, the only study published to date that succeeded in reducing the chloride burden did so by reducing every source of chloride, and not resuscitation fluids alone [7]. It might also be important to distinguish the absolute chloride load from the relative increase of chloride compared to sodium level. Although balanced formulations are commercially available, many hypotonic maintenance solutions contain equal amounts of sodium and chloride and could therefore cause metabolic acidosis [40]. The latter phenomenon, however, was previously reported to be of minor clinical importance $[9,41]$.

\section{Conclusions}

Volume, sodium, and chloride overloads due to nonresuscitation solutions deserve more consideration than they were granted in fluid studies up till now and should lead to the downsizing or even avoidance of maintenance fluids whenever possible, whilst handling the need for sufficient electrolytes through concentrated administration. A well-considered strategy regarding the tonicity of maintenance solutions could be more effective in reducing the sodium and chloride burden than switching to a balanced resuscitation and replacement strategy. Strategies for combatting fluid creep could include, in consultation with the hospital's pharmacist, dissolving intravenous medication in smaller volumes, using glucose instead of saline whenever possible, or switching to orally administered medications.

\section{Electronic supplementary material}

The online version of this article (https://doi.org/10.1007/s00134-018-5147-3) contains supplementary material, which is available to authorized users.

\footnotetext{
Author details

${ }^{1}$ Department of Intensive Care Medicine, Antwerp University Hospital, Wilrijkstraat 10, 2650 Edegem, Antwerp, Belgium. ${ }^{2}$ Department of Intensive Care Medicine, Ziekenhuis Netwerk Antwerpen Campus Stuivenberg, Lange Beeldekensstraat 267, 2060 Antwerp, Belgium. ${ }^{3}$ Clinical Trial Center (CTC), Clinical Research Center Antwerp, Antwerp University Hospital, University of Antwerp, Wilrijkstraat 10, 2650 Edegem, Antwerp, Belgium. ${ }^{4}$ Department of Nuclear Medicine, Antwerp University Hospital, Wilrijkstraat 10,
}

2650 Edegem, Antwerp, Belgium. ${ }^{5}$ Faculty of Medicine and Health Sciences, University of Antwerp, Universiteitsplein 1, 2610 Antwerp, Belgium.

\section{Acknowledgements}

The International Fluid Academy (www.fluidacademy.org) provided an educational grant to cover the open access publication costs for this article.

\section{Compliance with ethical standards}

\section{Conflicts of interest}

All authors declare that they have no conflicts of interest.

\section{Open Access}

This article is distributed under the terms of the Creative Commons Attribution-NonCommercial 4.0 International License (http://creativecommons.org/ licenses/by-nc/4.0/), which permits any noncommercial use, distribution, and reproduction in any medium, provided you give appropriate credit to the original author(s) and the source, provide a link to the Creative Commons license, and indicate if changes were made.

Received: 21 December 2017 Accepted: 8 March 2018

Published online: 27 March 2018

\section{References}

1. Perner A, Haase N, Guttormsen AB, Tenhunen J, Klemenzson G, Aneman A et al (2012) Hydroxyethyl starch 130/0.42 versus Ringer's acetate in severe sepsis. N Engl J Med 367(2):124-134

2. Myburgh JA, Finfer S, Bellomo R, Billot L, Cass A, Gattas D et al (2012) Hydroxyethyl starch or saline for fluid resuscitation in intensive care. $\mathrm{N}$ Engl J Med 367(20):1901-1911

3. Finfer S, Bellomo R, Boyce N, French J, Myburgh J, Norton R et al (2004) A comparison of albumin and saline for fluid resuscitation in the intensive care unit. N Engl J Med 350(22):2247-2256

4. Caironi P, Tognoni G, Masson S, Fumagalli R, Pesenti A, Romero M et al (2014) Albumin replacement in patients with severe sepsis or septic shock. N Engl J Med 370(15):1412-1421

5. Young P, Bailey M, Beasley R, Henderson S, Mackle D, McArthur C et al (2015) Effect of a buffered crystalloid solution vs saline on acute kidney injury among patients in the intensive care unit: the SPLIT randomized clinical trial. JAMA 314(16):1701-1710

6. Semler MW, Wanderer JP, Ehrenfeld JM, Stollings IL, SelfWH, Siew ED et al (2017) Balanced crystalloids versus saline in the intensive care unit. The SALT randomized trial. Am J Respir Crit Care Med 195(10):1362-1372

7. Yunos NM, Bellomo R, Hegarty C, Story D, Ho L, Bailey M (2012) Association between a chloride-liberal vs chloride-restrictive intravenous fluid administration strategy and kidney injury in critically ill adults. JAMA 308(15):1566-1572

8. Chowdhury AH, Cox EF, Francis ST, Lobo DN (2012) A randomized, controlled, double-blind crossover study on the effects of 2-L infusions of $0.9 \%$ saline and plasma-lyte ${ }^{\circledR} 148$ on renal blood flow velocity and renal cortical tissue perfusion in healthy volunteers. Ann Surg 256(1):18-24

9. Van Regenmortel N, Verbrugghe W, Van den Wyngaert T, Jorens PG (2016) Impact of chloride and strong ion difference on ICU and hospital mortality in a mixed intensive care population. Ann Intensive Care 6(1):91

10. Lobo DN, Awad S (2014) Should chloride-rich crystalloids remain the mainstay of fluid resuscitation to prevent 'pre-renal'acute kidney injury?: con. Kidney Int 86(6):1096-1105

11. Sullivan SR, Friedrich JB, Engrav LH, Round KA, Heimbach DM, Heckbert SR et al (2004) "Opioid creep" is real and may be the cause of "fluid creep". Burns 30(6):583-590

12. Saffle JI (2007) The phenomenon of "fluid creep" in acute burn resuscitation. J Burn Care Res 28(3):382-395

13. Vincent JL, Sakr Y, Sprung CL, Ranieri VM, Reinhart K, Gerlach H et al (2006) Sepsis in European intensive care units: results of the SOAP study. Crit Care Med 34(2):344-353

14. Moreno RP, Metnitz PG, Almeida E, Jordan B, Bauer P, Campos RA et al (2005) SAPS 3-from evaluation of the patient to evaluation of the 
intensive care unit. Part 2: development of a prognostic model for hospital mortality at ICU admission. Intensive Care Med 31(10):1345-1355

15. National Institute for Health and Care Excellence (2013) Guideline for intravenous fluid therapy in adults in hospital (CG174), 2013; updated May 2017. NICE, London

16. Bihari S, Watts NR, Seppelt I, Thompson K, Myburgh A, Prakash S et al (2016) Maintenance fluid practices in intensive care units in Australia and New Zealand. Crit Care Resusc 18(2):89-94

17. Bihari S, Peake SL, Seppelt I, Williams P, Bersten A, George Institute for Global Health et al (2013) Sodium administration in critically ill patients in Australia and New Zealand: a multicentre point prevalence study. Crit Care Resusc 15(4):294-300

18. Bihari S, Ou J, Holt AW, Bersten AD (2012) Inadvertent sodium loading in critically ill patients. Crit Care Resusc 14(1):33-37

19. Bihari S, Peake SL, Prakash S, Saxena M, Campbell V, Bersten A (2015) Sodium balance, not fluid balance, is associated with respiratory dysfunction in mechanically ventilated patients: a prospective, multicentre study. Crit Care Resusc 17(1):23-28

20. Bihari S, Baldwin CE, Bersten AD (2013) Fluid balance does not predict estimated sodium balance in critically ill mechanically ventilated patients. Crit Care Resusc 15(2):89-96

21. Van Regenmortel $\mathrm{N}$, De Weerdt $\mathrm{T}$, Van Craenenbroeck AH, Roelant $\mathrm{E}_{,}$ Verbrugghe W, Dams K et al (2017) Effect of isotonic versus hypotonic maintenance fluid therapy on urine output, fluid balance, and electrolyte homeostasis: a crossover study in fasting adult volunteers. Br J Anaesth 118(6):892-900

22. McNab S, Duke T, South M, Babl FE, Lee KJ, Arnup SJ et al (2015) $140 \mathrm{mmol} / \mathrm{L}$ of sodium versus $77 \mathrm{mmol} / \mathrm{L}$ of sodium in maintenance intravenous fluid therapy for children in hospital (PIMS): a randomised controlled double-blind trial. Lancet 385(9974):1190-1197

23. Holliday MA, Ray PE, Friedman AL (2007) Fluid therapy for children: facts, fashions and questions. Arch Dis Child 92(6):546-550

24. Leroy PL, Hoorn EJ (2017) Should we use hypotonic or isotonic maintenance intravenous fluids in sick patients? Why a study in healthy volunteers will not provide the answer: Response to: Effect of isotonic versus hypotonic maintenance fluid therapy on urine output, fluid balance, and electrolyte homeostasis: a crossover study in fasting adult volunteers. Br J Anaesth 119(4):836-837

25. Moritz ML, Ayus JC (2017) Hypotonic maintenance i.v. fluids are not appropriate in acutely ill patients. Conclusions can't be extrapolated from healthy volunteers. Br J Anaesth 119(5):1064-1065

26. Van Regenmortel N, Jorens PG (2017) Effect of isotonic vs hypotonic maintenance fluid therapy on urine output, fluid balance, and electrolyte homeostasis: a crossover study in fasting adult volunteers. Reply from the authors. Br J Anaesth 119(5):1065-1067

27. Hendrickx S, Van Vlimmeren K, Baar I, Verbrugghe W, Dams K, Van Cromphaut $S$ et al (2017) Introducing TOPMAST, the first double-blind randomized clinical trial specifically dedicated to perioperative maintenance fluid therapy in adults. Anaesthesiol Intensive Ther 49(5):366-372

28. Bihari S, Festa M, Peake SL, Seppelt IM, Williams P, Wilkins B et al (2014) Sodium administration in critically ill paediatric patients in Australia and New Zealand: a multicentre point prevalence study. Crit Care Resusc 16(2):112-118

29. Langer T, Santini A, Scotti E, Van Regenmortel N, Malbrain ML, Caironi $P(2015)$ Intravenous balanced solutions: from physiology to clinical evidence. Anaesthesiol Intensive Ther 47:78-88

30. Shaw AD, Bagshaw SM, Goldstein SL, Scherer LA, Duan M, Schermer CR et al (2012) Major complications, mortality, and resource utilization after open abdominal surgery: $0.9 \%$ saline compared to Plasma-Lyte. Ann Surg 255(5):821-829

31. Hansen PB, Jensen BL, Skott O (1998) Chloride regulates afferent arteriolar contraction in response to depolarization. Hypertension 32(6):1066-1070

32. Trissel LA (2009) Handbook on injectable drugs. American Society of Hospital Pharmacists, Bethesda, MD

33. Rosenberg AL, Dechert RE, Park PK, Bartlett RH, Network NNA (2009) Review of a large clinical series: association of cumulative fluid balance on outcome in acute lung injury: a retrospective review of the ARDSnet tidal volume study cohort. J Intensive Care Med 24(1):35-46

34. Murphy CV, Schramm GE, Doherty JA, Reichley RM, Gajic O, Afessa B et al (2009) The importance of fluid management in acute lung injury secondary to septic shock. Chest 136(1):102-109

35. Bagshaw SM, Brophy PD, Cruz D, Ronco C (2008) Fluid balance as a biomarker: impact of fluid overload on outcome in critically ill patients with acute kidney injury. Crit Care 12(4):169

36. Vaara ST, Korhonen AM, Kaukonen KM, Nisula S, Inkinen O, Hoppu S et al (2012) Fluid overload is associated with an increased risk for 90-day mortality in critically ill patients with renal replacement therapy: data from the prospective FINNAKI study. Crit Care 16(5):R197

37. Bouchard J, Soroko SB, Chertow GM, Himmelfarb J, Ikizler TA, Paganini EP et al (2009) Fluid accumulation, survival and recovery of kidney function in critically ill patients with acute kidney injury. Kidney Int 76(4):422-427

38. Balogh Z, McKinley BA, Cocanour CS, Kozar RA, Holcomb JB, Ware DN et al (2002) Secondary abdominal compartment syndrome is an elusive early complication of traumatic shock resuscitation. Am J Surg 184(6):538-543 (discussion 543-544)

39. Lobo DN, Bostock KA, Neal KR, Perkins AC, Rowlands BJ, Allison SP (2002) Effect of salt and water balance on recovery of gastrointestinal function after elective colonic resection: a randomised controlled trial. Lancet 359(9320):1812-1818

40. Kellum JA (1998) Metabolic acidosis in the critically ill: lessons from physical chemistry. Kidney Int 66:S81-S86

41. Gunnerson KJ, Saul M, He S, Kellum JA (2006) Lactate versus non-lactate metabolic acidosis: a retrospective outcome evaluation of critically ill patients. Crit Care 10(1):R22 